\title{
INTERCONECTIVIDADE DE AQUÍFEROS E OS EFEITOS DA DRENAGEM ÁCIDA DE MINA NA QUALIDADE DAS ÁGUAS DA BACIA CARBONÍFERA DE SANTA CATARINA (SC)
}

\section{AQUIFER INTERCONNECTIVITY AND THE EFFECTS OF MINING ACID DRAINAGE ON THE QUALITY OF THE WATERS OF THE SANTA CATARINA CARBONIFEROUS BASIN}

\author{
Marlon HOELZEL ${ }^{1,2}$, Ana Maria Pimentel MIZUSAKI ${ }^{1}$ \\ ${ }^{1}$ Programa de Pós-Graduação em Geociências - Universidade Federal do Rio Grande do Sul. Campus do Vale. Avenida Bento \\ Gonçalves, 9.500. Porto Alegre - RS. E-mails: marlon.hoelzel@cprm.gov.br; ana.mizusaki@ufrgs.br \\ ${ }^{2}$ Serviço Geológico do Brasil - CPRM. R. Banco da Província, 105 - Santa Tereza, Porto Alegre - RS \\ Introdução \\ Área de Estudo \\ Metodologia \\ Resultados \\ Discussões \\ Conclusões \\ Agradecimentos \\ Referências
}

\begin{abstract}
RESUMO - A atividade carbonífera no sul de Santa Catarina se desenvolve há mais de um século e a falta de gerenciamento ambiental nos empreendimentos mineiros causou significativas alterações de qualidade nos recursos hídricos da Bacia Hidrográfica do Araranguá. Além da alteração na qualidade das águas, ocorreram fenômenos de colapso e abatimento de minas subterrâneas que ocasionaram fraturamento das camadas sobrejacentes, e permitiram a ampliação dos processos de interação dos sistemas aquíferos com corpos hídricos superficiais. Com objetivo de melhorar o entendimento destes processos, foram analisadas amostras das águas de 9 poços do Sistema Aquífero Rio Bonito, 4 poços do Sistema Aquífero de Leques Aluviais e 6 amostras de águas superficiais das mesmas microbacias onde estão instalados os poços. As análises hidroquímicas indicam uma predominância de águas bicarbonatadas cálcicas e sódicas, que quando em contato com a drenagem ácida de mina são transformadas em águas sulfatadas. A composição isotópica em termos de isótopos de oxigênio e de hidrogênio das amostras evidencia semelhança com a composição isotópica das águas meteóricas. Este fato contribui com a hipótese da forte interação das águas subterrâneas com as águas freáticas e superficiais, que ocorre devido à tectônica rúptil que afeta as litologias gondwânicas, e é intensificada pela presença das minas de subsolo.

Palavras-chave: Hidroquímica, Isótopos estáveis, Àgua subterrânea, Drenagem ácida de mina.
\end{abstract}

\begin{abstract}
Carboniferous activity in southern Santa Catarina State has been developed over a century and the lack of environmental management in mining projects caused significant changes in the water resources of the Araranguá Watershed. In addition to changes in water quality, collapses in underground mines caused the fracturing of overlying layers allowing the expansion of aquifer systems and surface waters interaction processes. In order to better understand these processes, samples of 9 wells from Rio Bonito Aquifer System, 4 wells from Alluvial Fan Aquifer System and 6 from surface waters of the same catchments were analyzed. Hydrochemical analysis indicates a predominance of calcium and sodium bicarbonate waters which in contact with acid mine drainage are transformed into sulfated waters. The isotopic composition of the samples shows similarity to the isotopic composition of meteoric waters, contributing to the hypothesis of the strong interaction between groundwater, waters from water table and surface waters, which occurs due to the brittle tectonics affecting gondwanic lithologies, and is intensified by the presence of underground mines.
\end{abstract}

Keywords: Hydrochemistry, Stable isotopes, Groundwater, Acid mine drainage.

\section{INTRODUÇÃO}

A mineração do carvão é parte fundamental da economia da região sul do Estado de Santa Catarina e para alguns municípios constitui-se na essência da sua própria história (Belolli et al., 2002). Nesta região, situa-se a bacia carbonífera de Santa Catarina (Figura 1), que possuiu grande importância econômica no setor energético e siderúrgico do país, e atualmente representa $63 \%$ do faturamento do setor carbonífero, e que vem sendo explorada desde o final do século XIX. Segundo estimativas do governo federal, as suas reservas ainda seriam suficientes para suprir mais 500 anos de produção (ANEEL, 2017).
$\mathrm{Na}$ mesma proporção que o carvão trouxe desenvolvimento para as cidades do sul catarinense, também provocou diversos impactos ambientais, principalmente nos recursos hídricos (Amaral \& Krebs, 2010). Um dos mais graves impactos ambientais originados pela mineração do carvão são os efeitos da Drenagem Ácida de Mina (DAM), gerada a partir da oxidação de sulfetos metálicos presentes no minério. Esta oxidação ocorre quando os sulfetos são expostos aos processos atmosféricos, que em contato com a água geram efluentes ácidos, com elevadas concentrações de sulfato e de metais pesados, 
responsáveis pela rápida degradação de disponibilidade hídrica para o abastecimento ambientes aquáticos e pela redução da público e outros usos (Mello et al., 2014).

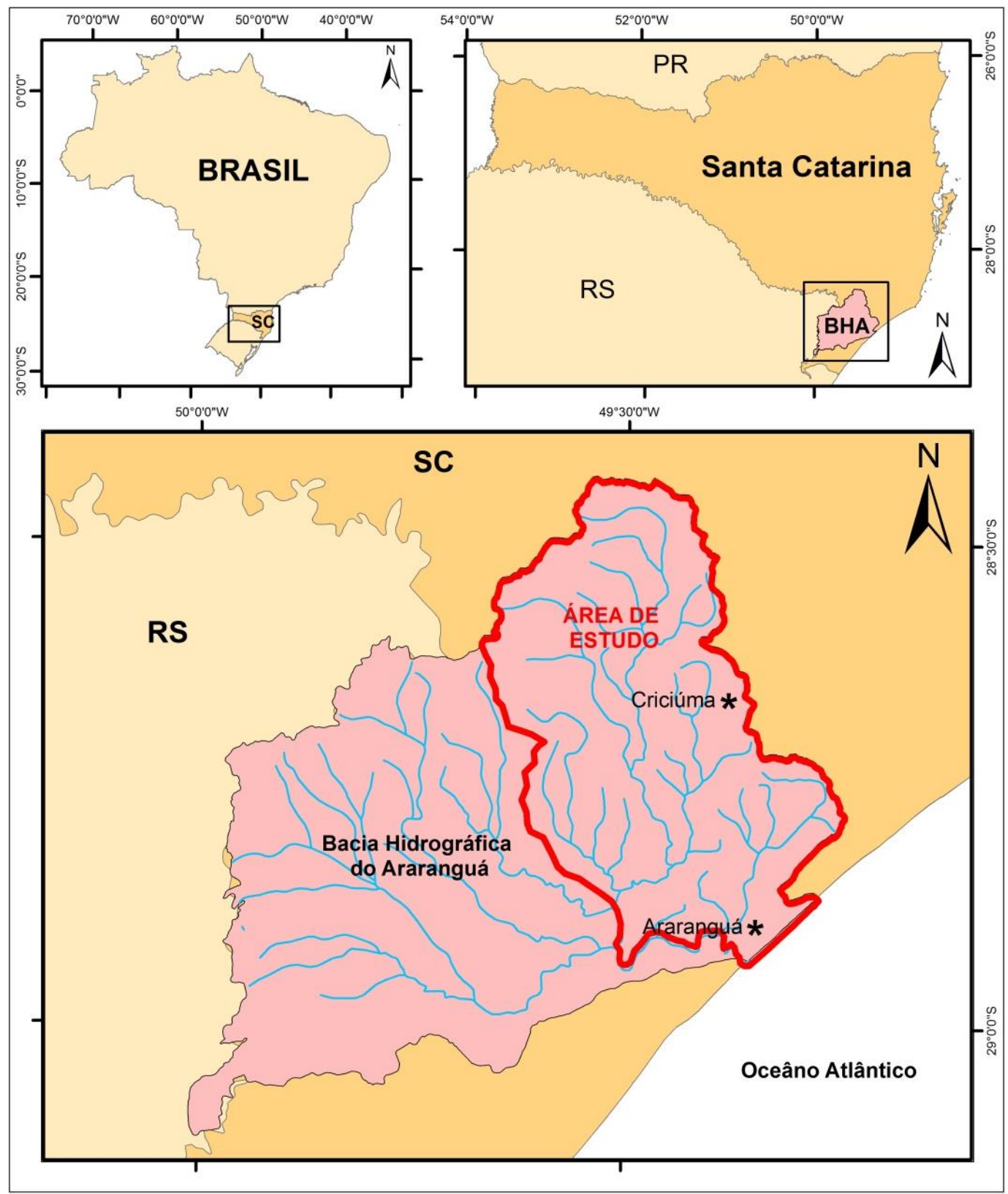

Figura 1 - Localização da Bacia Hidrográfica do Araranguá, na região sul do Estado de Santa Catarina, destacando-se a área de estudo formada pelas Sub-bacias dos rios Mãe Luzia, Sangão e dos Porcos (modificado de IBGE, 2016 -SIRGAS, 2000).

Os impactos ambientais gerados por esta atividade mineira afetam os recursos hídricos da Bacia Hidrográfica do Araranguá, que concentra aproximadamente $80 \%$ das atividades carboníferas desenvolvidas na região, provocando intensa degradação dos recursos hídricos. Ao longo das décadas de mineração do carvão, diversos fenômenos de colapso e abatimento de minas subterrâneas foram ocasionados pela presença de falhas geológicas ou pela retirada de pilares de sustentação, gerando intenso faturamento nas camadas sobrejacentes, permitindo ou ampliando a interconexão dos sistemas aquíferos com corpos hídricos superficiais.

Esta degradação ambiental presente na região motivou o Ministério Público Federal a mover uma ação civil pública, que condenou solidariamente a União Federal e as empresas mineradoras a promoverem a recuperação ambiental dos seus passivos, e desde então, a recuperação ambiental vem sendo implementada nas áreas degradadas pela mineração do carvão, com o principal objetivo de restabelecer a função ecológica e social dos ambientes terrestres e promover a recuperação dos recursos hídricos 
superficiais e subterrâneos da região (GTA, 2018).

Neste contexto, o presente trabalho possui objetivo de melhorar o entendimento dos processos de circulação entre os diferentes níveis aquíferos e das relações entre as águas subterrâneas e as águas superficiais, através da combinação dos resultados de análises de isótopos estáveis $\left(\delta^{2} \mathrm{He} \delta^{18} \mathrm{O}\right)$, com informações hidroquímicas e hidrogeológicas.

\section{ÁREA DE ESTUDO}

A Bacia Hidrográfica do Araranguá ocupa uma área de aproximadamente $3.020 \mathrm{~km}^{2}$ localizada na região sul do Estado de Santa Catarina e está inserida no contexto geológico regional da Bacia do Paraná. A sedimentação vulcano-sedimentar da Bacia do Paraná pode ser subdividida em seis supersequências, com idades que variam desde o Ordoviciano até o Cretáceo (Milani et al., 2007) (Figura 2).

$\mathrm{Na}$ área de estudo há o domínio da Supersequência Gondwana I, sendo marcada pelo declínio das condições glaciais do Permiano, quando se depositaram as rochas sedimentares plataformais da Formação Rio Bonito, sobrepostas pelos siltitos de ambiente marinho raso da Formação Palermo (Milani et al., 2007). Ocorrem também extensas coberturas quaternárias denominadas de depósitos de leques aluviais (Krebs, 2004), que cobrem uma área de 1.088 km² correspondendo a $36 \%$ da superfície da bacia hidrográfica. Como embasamento cristalino são reconhecidas rochas graníticas e gnáissicas da Suíte Pedras Grandes e do Batólito de Florianópolis (Bitencourt et al., 2008).

As litologias da Formação Rio Bonito (Figura 2) que afloram na porção leste da Bacia Hidrográfica do Araranguá, foram individualizadas em três membros, denominados Triunfo, Paraguaçu e Siderópolis (Mühlmann et al., 1974). Constituem um espesso pacote de arenitos de granulometria fina a média, com estratificações plano-paralelas, cruzadas tabulares e cruzadas acanaladas, intercalados com siltitos e folhelhos carbonosos, com laminação plano paralela, eventualmente ondulada. Observa-se um aumento do predomínio dos siltitos e folhelhos em direção ao topo da sequência, evidenciando o trato marinho transgressivo. A porção mais arenosa da Formação Rio Bonito é a porção do terço superior, correspondente ao Membro Siderópolis, que concentra as camadas de carvão denominadas Camada Bonito, Barro Branco e Irapuá, que possuem teores variados de sulfetos de ferro $\left(\mathrm{FeS}_{2}\right)$ disseminados nas camadas de carvão e nas encaixantes (Krebs, 2004).

As litologias arenosas da Formação Rio Bonito constituem o Sistema Aquífero Rio Bonito, que possui elevada capacidade de armazenamento e transmissão de água, caracterizando-se como um importante aquífero para a região. Na porção leste da Bacia Hidrográfica do Rio Araranguá onde as litologias da Formação Rio Bonito são aflorantes, o aquífero ocorre de forma livre com comportamento de aquífero poroso.

$\mathrm{Na}$ área de estudo, as litologias da Formação Rio Bonito estão afetadas por conjuntos de falhas rúpteis associadas a diversos eventos tectônicos, sendo que os principais sistemas de falhas possuem direção principal NW-SE, e foram formados entre 133 a $135 \mathrm{Ma}$ no processo de abertura do Gondwana, e posteriormente reativados entre 90 e $66 \mathrm{Ma}$, com o soerguimento regional do domo de Lages (Petry et al., 2017).

Krebs (2004) mostra que na Bacia Carbonífera de Santa Catarina, as rochas gondwânicas registram maior densidade de lineamentos estruturais do que outras áreas da Bacia do Paraná e considera que as falhas $\mathrm{N} 30^{\circ} \mathrm{W}$ são do ponto de vista hidrogeológico, são estruturas importantes para a armazenagem, circulação, recarga e descarga de água.

A Formação Palermo se caracteriza como um espesso pacote de ritmitos, compostos por intercalações de siltitos e argilitos, que na área de estudo se constituem em aquitardos e confinam as águas subterrâneas do Sistema Aquífero Rio Bonito (Krebs, 2004).

As coberturas cenozoicas que ocorrem na área de estudo são denominadas de Leques Aluviais, constituídos por sedimentos inconsolidados, com predomínio de cascalhos e seixos na base e areias e lamas no topo. São depósitos de geometria lenticular, gerados a partir de fluxos torrenciais, desde o Plioceno ao Recente. As espessuras são da ordem de $5 \mathrm{~m}$ no limite leste da Bacia, aumentando gradativamente para oeste, onde podem chegar a $40 \mathrm{~m}$ (Krebs, 2004). Estas coberturas possuem regime hidrogeológico de aquífero granular livre ou semi confinados por lentes argilosas, denominado de Sistema Aquífero de Leques Aluviais. O nível freático deste sistema aquífero possui relação direta com as taxas de pluviosidade, 
visto que são recarregados pela chuva e pelos rios em grandes momentos de deflúvio, e também podem alimentar e garantir o fluxo de base dos rios em épocas de estiagem. Trata-se de um aquífero

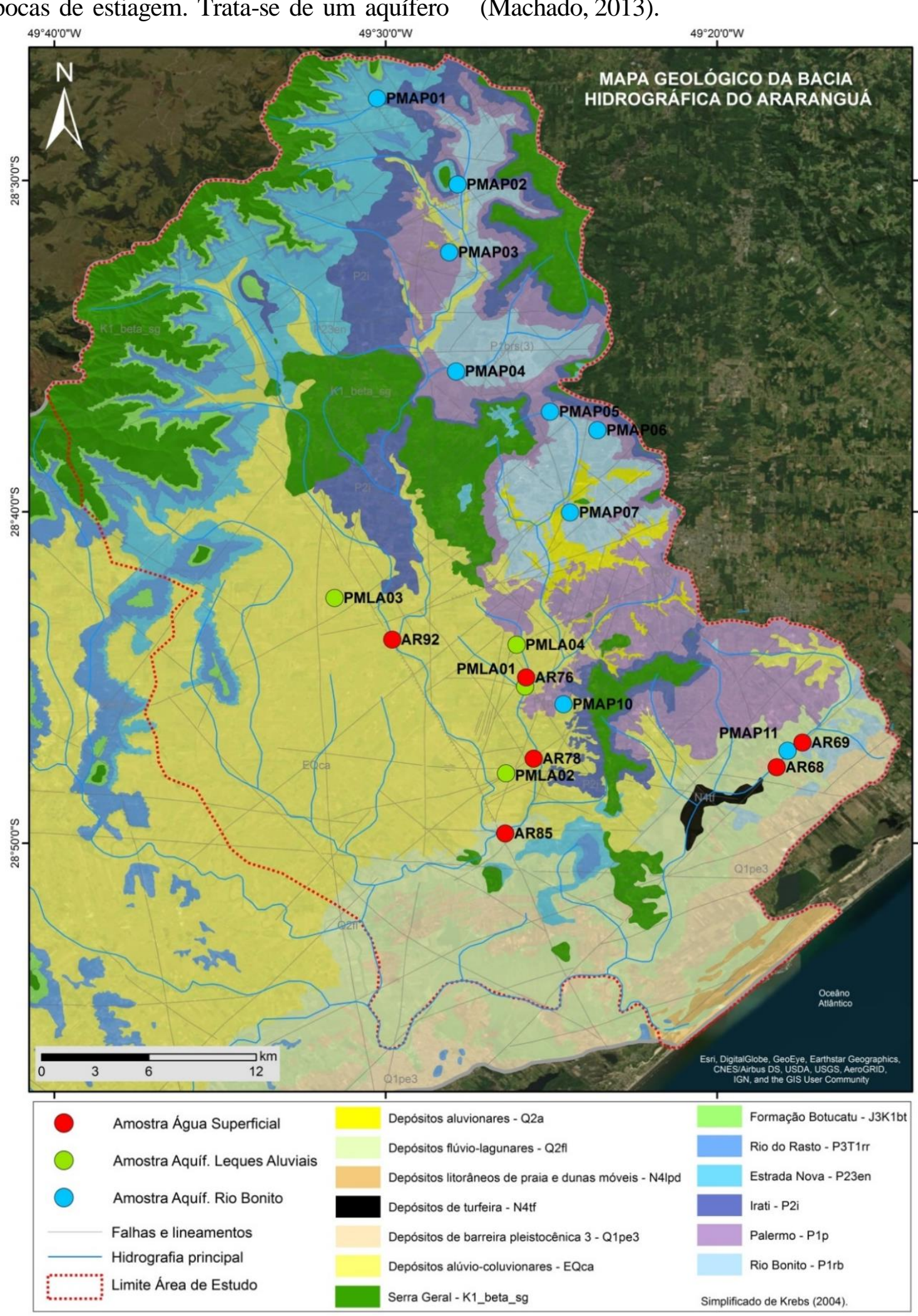

Figura 2 - Mapa geológico e estrutural com localização dos pontos de amostragem de água superficial e água subterrânea da área de estudo (modificado de Krebs, 2004).

Ao longo das décadas de mineração do carvão, hídricos. Os principais impactos se referem à observam-se diversos tipos de impactos ambientais geração de drenagem ácida de mina, que é um que atuam diretamente na qualidade dos recursos fenômeno que se inicia quando rochas contendo 
minerais sulfetados são retiradas do subsolo pelas atividades de mineração e dispostos na superfície em contato com água e oxigênio atmosféricos (Figura 5B).

Os recursos hídricos na sub-bacia do Rio Sangão, podem ser subdivididos em trechos com influência da drenagem ácida de mina e trechos sem influência (Farfan et al., 2004) (Figura 3). Observa-se que os trechos influenciados pela mineração do carvão possuem uma redução de $\mathrm{pH}$ para a faixa de 2,0 a 4,0, e aumento das concentrações de ferro, alumínio, manganês, zinco e sulfato.

Outra importante alteração das condições ambientais se refere à presença de áreas mineradas em subsolo (Figura 4), em que a presença de descontinuidades e falhas geológicas ocasionou diversos fenômenos de colapso e abatimento de minas subterrâneas, ampliando o fraturamento das camadas sobrejacentes, e intensificando os processos de interconexão dos sistemas aquíferos com corpos hídricos superficiais. Esta interconexão é demonstrada no trabalho realizado por Leão \& Krebs (2017) indicando que falhas geológicas permitiram o colapso de minas subterrâneas e a conexão do Sistema Aquífero Rio Bonito com as águas superficiais, com condutividade hidráulica de $4,65 \mathrm{~m} / \mathrm{hora}$.

\begin{tabular}{|c|c|c|}
\hline Parâmetro & $\begin{array}{c}\text { Rio sem influência da } \\
\text { mineração de carvão }\end{array}$ & $\begin{array}{c}\text { Rio com influência da } \\
\text { mineração de carvão }\end{array}$ \\
\hline $\mathrm{pH}$ & 6,5 a 7,4 & 2,0 a 4,0 \\
\hline $\mathrm{SO}_{4}^{-}$ & 8,0 a $25,0(\mathrm{mg} / \mathrm{L})$ & 10 a $1000(\mathrm{mgL})$ \\
\hline $\mathrm{Fe}$ total & $<4,0(\mathrm{mg} / \mathrm{L})$ & 10 a $100(\mathrm{mg} / \mathrm{L})$ \\
\hline $\mathrm{Al}$ & 0,2 a $0,5 \mathrm{mg} / \mathrm{L}$ & 10 a $100(\mathrm{mg} / \mathrm{L})$ \\
\hline $\mathrm{Zn}$ & $\mathrm{ND}$ & 1,0 a $5,0(\mathrm{mg} / \mathrm{L})$ \\
\hline $\mathrm{Mn}$ & $\mathrm{ND}$ & 0,5 a $10(\mathrm{mg} / \mathrm{L})$ \\
\hline $\mathrm{Pb}$ & $\mathrm{ND}$ & 0,02 a $0,2(\mathrm{mg} / \mathrm{L})$ \\
\hline
\end{tabular}

Figura 3 - Diferença dos parâmetros físico-químicos das águas do Rio Sangão em trechos com influência de drenagem ácida e sem influência da drenagem ácida (Farfan et al., 2004).

\section{METODOLOGIA}

Uma etapa fundamental em qualquer investigação de águas subterrâneas é a definição e mapeamento das unidades aquíferas e confinantes (unidades hidroestratigráficas), e com o delineamento dessas unidades, fragmentase o arcabouço geológico em função de sua permeabilidade, procurando-se definir o sistema de fluxo (Machado \& Freitas, 2005).

Para a realização deste estudo, foram utilizados dados de análises físico-químicas do monitoramento sistemático dos recursos hídricos da Bacia Carbonífera de Santa Catarina, executado pelo Serviço Geológico do Brasil e disponibilizado no $11^{\circ}$ Relatório de Indicadores Ambientais (GTA, 2018). Em complemento aos dados físico-químicos, foi realizada uma campanha de amostragem das águas para análises isotópicas de oxigênio $\left(\delta^{18} \mathrm{O}\right)$ e hidrogênio $\left(\delta^{2} \mathrm{H}\right)$. Esta amostragem foi simultânea à coleta da campanha de monitoramento executada pelo Serviço Geológico do Brasil (CPRM, 2017). Inicialmente a pesquisa reuniu os dados de mapas geológico/estrutural, mapa hidrogeológico e informações hidroquímicas da região de estudo. A partir dos dados disponíveis, procedeu-se a seleção dos pontos de amostragem para análise isotópica das águas, levando em consideração a proximidade entre os pontos de amostragem de água superficial com os poços de monitoramento de água subterrânea, limitados à Bacia Hidrográfica do Araranguá (SC).

Após a seleção dos pontos de amostragem e com as informações sobre a geologia, hidrogeologia, arcabouço estrutural, pontos de amostragem, hidrografia, áreas degradadas pela mineração a céu aberto (Figura 5A, B) e delimitação de galerias de minas subterrâneas, foi elaborado um banco de dados em ambiente SIG, com utilização de software de geoprocessamento.

A amostragem da água superficial e subterrânea (Figura 5C, D) ocorreu durante o mês de junho de 2017 e foi realizada em 19 pontos de monitoramento, das quais 9 amostras foram coletadas em poços de monitoramento instalados no Sistema Aquífero Rio Bonito, 4 amostras em poços instalados no Sistema Aquífero de Leques Aluviais e 6 amostras de águas superficiais provenientes dos córregos da Bacia Hidrográfica do Araranguá. As águas superficiais foram coletadas diretamente dos 
córregos, em dois frascos de polipropileno de $1 \mathrm{~L}$ para cada ponto de coleta, com a adição de $20 \mathrm{~mL}$ de $\mathrm{HCl}$ para preservação da análise dos cátions. As amostras de água subterrânea também seguiram o mesmo protocolo de preservação, e foram coletadas conforme a NBR 15.847 (ABNT, 2010) por meio da técnica de purga de

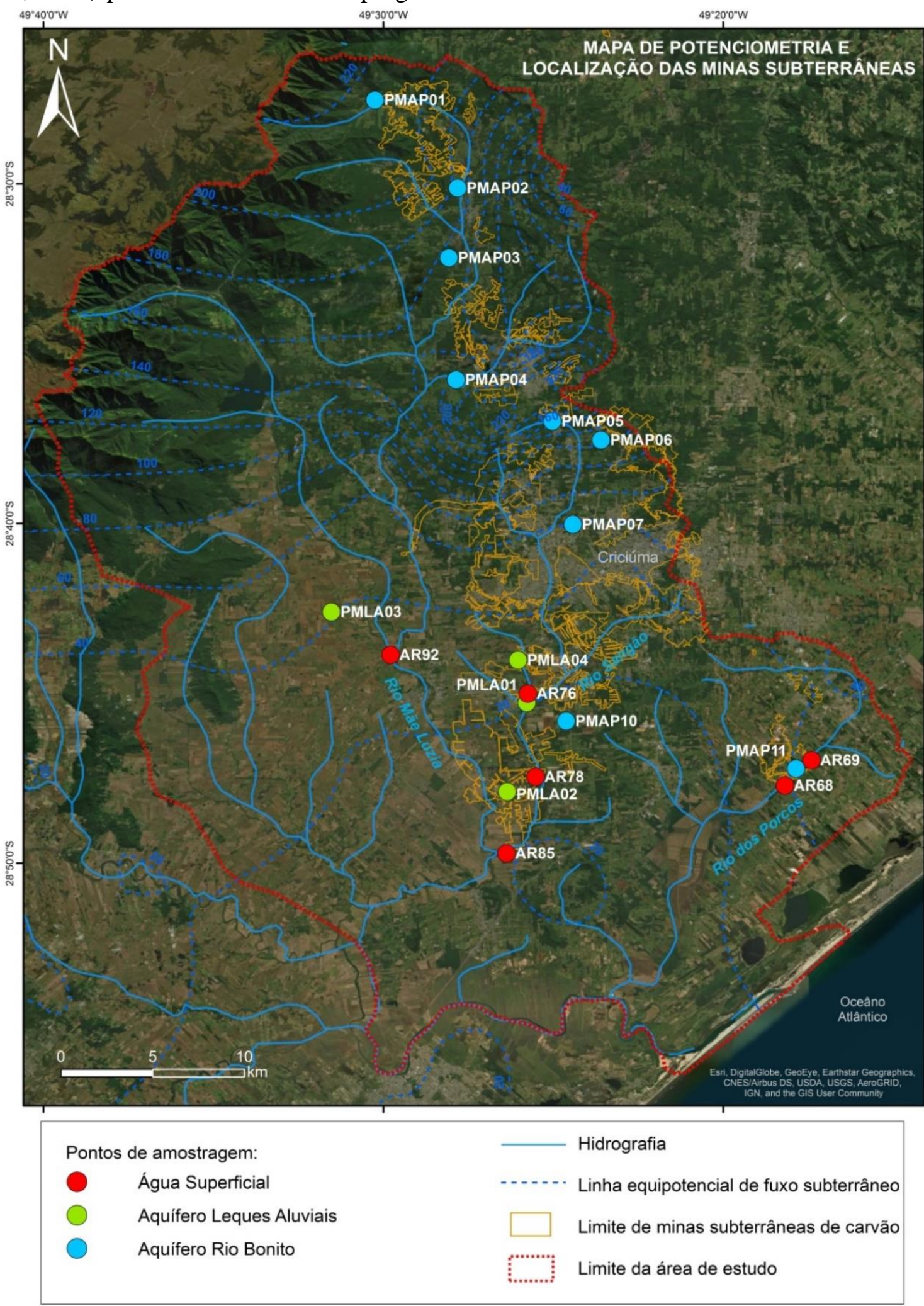

Figura 4 - Localização dos pontos de amostragem de água superficial e subterrânea (Aquíferos Rio Bonito e Leques Aluviais) e a localização das galerias de minas subterrânea. (modificado de DNPM, 2009). O mapa mostra as linhas equipotenciais do fluxo regional do aquífero Rio Bonito, com direção geral de NNW para SSE (modificado de Krebs, 2004).

São Paulo, UNESP, Geociências, v. 38, n. 4, p. 999 - 1015, 2019 


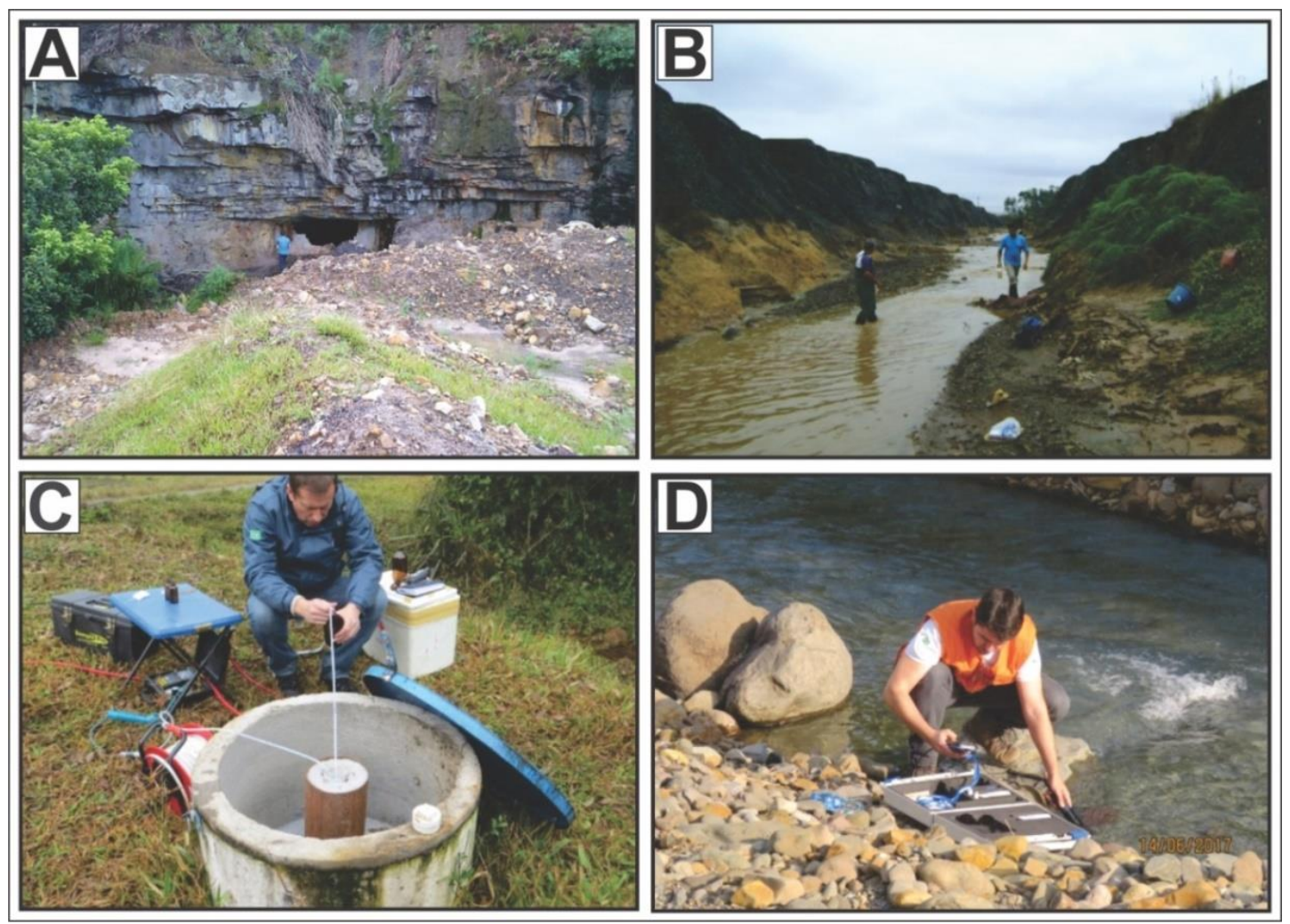

Figura 5 - A) Afloramento das camadas arenosas da Formação Rio Bonito em área minerada a céu aberto (Município de Treviso; 22J 659299/6847967; CPRM, 2015); B) depósito de rejeitos da mineração do carvão sobre sedimentos cenozoicos na margem do Rio Maina (Município de Criciúma; 22J 653990/6827140; CPRM, 2009); C) amostragem de água subterrânea em poço de monitoramento pelo método de baixa vazão (Município de Siderópolis; 22J 654930/6833159; CPRM, 2017; D) medição dos parâmetros de qualidade e amostragem de água superficial no Rio Mãe Luzia (Município de Treviso; 22J 650496/6843484; CPRM, 2017).

Os poços de monitoramento utilizados neste estudo foram instalados entre os anos de 2009 e 2016 pelo Projeto de Monitoramento dos Recursos Hídricos da Bacia Carbonífera de Santa Catarina, executado pelo convênio entre o Serviço Geológico do Brasil (CPRM), Sindicato da Indústria de Extração do Carvão do Estado de Santa Catarina (SIECESC) e Ministério de Meio Ambiente (MMA). Estes poços foram construídos conforme NBR 15.495-1 (ABNT, 2007), e captam água somente do intervalo aquífero de interesse, uma vez que as entradas de água de níveis mais rasos são completamente isoladas por calda de concreto e bentonita. A figura 6 apresenta as informações das amostras obtidas nestes poços de monitoramento.

Os pontos de amostragem para a água superficial foram determinados a partir da localização dos poços perfurados no Sistema Aquífero de Leques Aluviais e estão descritos na figura 7.

As análises isotópicas foram realizadas durante o mês de julho de 2017 no Laboratório de Hidroquímica do Centro de Estudo de Bacias (LEBAC), do Instituto de Geociências e Ciências Exatas (IGCE) da Universidade Estadual Paulista
(UNESP, Rio Claro). As amostras PMAP11, AR68, AR76, AR78 e AR85 (Figura 6 e 7), segundo protocolos do Laboratório de Hidroquímica do Centro de Estudos de Bacias (LEBAC), foram consideradas como hipersalinas, sendo necessário serem submetidas a um processo de destilação em sistema fechado. Este processo de destilação visou reduzir a salinidade das amostras e o sistema fechado impede eventual fracionamento garantindo a preservação das razões isotópicas. A redução da salinidade é necessária por fatores de fracionamento entre $\mathrm{CO}_{2}$ e $\mathrm{H}_{2} \mathrm{O}$, dependentes da salinidade e que irão normalmente acarretar na perda de exatidão (Christophe et al., 2009).

As determinações dos valores das razões foram efetuadas pela Técnica de Espectroscopia a Laser empregando analisadores de isótopos, modelos LWIA-24-EP e TLWIA-45-EP da Los Gatos Research, com erros associados de $\delta^{2} \mathrm{H}$ $(\%)=1.2$ e $\delta^{18} \mathrm{O}(\%)=0.40$.

As análises físico-químicas foram realizadas durante o mês de agosto de 2017 seguindo procedimentos do Standard Methods for the Examination of Water and Wastewater (1998) e realizadas no Centro de Controle de Poluição na 
Mineração (CECOPOMIN) do Serviço Geológico do Brasil em São Paulo.

A caracterização hidroquímica avaliou os dados referentes às análises físico-químicas de cada poço. Os dados foram processados no programa Qualigraf (Mobus, 2002), com o objetivo de efetuar a classificação dos tipos de águas associadas a cada compartimento hídrico. O programa Qualigraf gera o Diagrama de Piper e classifica as amostras segundo os íons dominantes. A representação gráfica pode evidenciar possíveis relações entre íons de uma mesma amostra, ou ressaltar variações temporais ou de um conjunto de amostras.

\begin{tabular}{|c|c|c|c|c|c|}
\hline Poço & UTM E-N & Sistema Aquifero & Litologias perfuradas & $\begin{array}{c}\text { Cota da } \\
\text { Boca }(\mathbf{m})\end{array}$ & $\begin{array}{c}\text { Profundidade } \\
\text { Final }(\mathbf{m})\end{array}$ \\
\hline PMAP01 & 22J $646700 / 6850778$ & Rio Bonito & Irati, Palermo, Rio Bonito & 294 & 138 \\
\hline PMAP02 & 22J 650605/6845935 & Rio Bonito & Palermo, Rio Bonito & 157 & 64 \\
\hline PMAP03 & 22J 650141/6842158 & Rio Bonito & Palermo, Rio Bonito & 131 & 80 \\
\hline PMAP04 & 22J 650390/6835515 & Rio Bonito & Rio Bonito & 85 & 60 \\
\hline PMAP05 & 22J 654982/6833202 & Rio Bonito & Rio Bonito & 73 & 50 \\
\hline PMAP06 & 22J $657295 / 6832144$ & Rio Bonito & Rio Bonito & 47 & 15 \\
\hline PMAP07 & 22J $655888 / 6827576$ & Rio Bonito & Rio Bonito & 43 & 15 \\
\hline PMAP10 & 22J $655426 / 6816887$ & Rio Bonito & Palermo, Rio Bonito & 22 & 8 \\
\hline PMAP11* & 22J $666427 / 6814058$ & Rio Bonito & Palermo, Rio Bonito & 9 & 62 \\
\hline PMLA01 & 22J $653550 / 6817903$ & Leques Aluviais & Depósitos aluvionares & 19 & 8 \\
\hline PMLA02 & 22J $652548 / 6813079$ & Leques Aluviais & Depósitos aluvionares & 20 & 1 \\
\hline PMLA03 & 22J $644256 / 6822962$ & Leques Aluviais & Depósitos aluvionares & 40 & 11 \\
\hline PMLA04 & 22J 653159/6820235 & Leques Aluviais & Depósitos aluvionares & 22 & 7 \\
\hline
\end{tabular}

Figura 6 - Relação das amostras de água subterrânea analisadas nos poços de monitoramento da Bacia Hidrográfica do Araranguá (ver Figura 1 e 2); (*) indica amostras de água posteriormente submetidas a processo de destilação em sistema fechado.

\begin{tabular}{|c|c|c|c|c|c|}
\hline $\begin{array}{l}\text { Estação } \\
\text { Coleta }\end{array}$ & UTM E-N & $\begin{array}{c}\text { Microbacia } \\
\text { (Rio) }\end{array}$ & Descrição & $\begin{array}{l}\text { Cota } \\
\text { (m) }\end{array}$ & $\begin{array}{l}\text { Vazão } \\
\text { (L/s) }\end{array}$ \\
\hline AR068* & 22J 666048/6814482 & dos Porcos & $\begin{array}{l}\text { Drenagem secundária margem direita do } \\
\text { Rio dos Porcos }\end{array}$ & 9 & 13,5 \\
\hline AR069 & 22J 666189/6814170 & dos Porcos & Rio dos Porcos à jusante do ponto AR068 & 9 & 100 \\
\hline AR076* & 22J $653602 / 6818062$ & Sangão & $\begin{array}{l}\text { Rio Sangão próximo da ponte rodoviária, } \\
\text { na localidade de São Roque }\end{array}$ & 19 & 614 \\
\hline AR078* & 22J $653735 / 6813795$ & Sangão & $\begin{array}{l}\text { Drenagem secundária da margem direita } \\
\text { do Rio Sangão }\end{array}$ & 14 & 9,5 \\
\hline AR085* & 22J 652309/6810343 & Sangão & Rio Sangão à montante do Rio Mãe Luzia & 12 & 631 \\
\hline AR092 & 22J 647006/6820556 & Mãe Luzia & $\begin{array}{l}\text { Rio Guarapari à montante do Rio Mãe } \\
\text { Luzia }\end{array}$ & 27 & 708 \\
\hline
\end{tabular}

Figura 7 - Relação de amostras de água superficial analisadas na Bacia Hidrográfica do Araranguá (ver Figura 1 e 2); (*) indica amostras de água posteriormente submetidas a processo de destilação em sistema fechado.

\section{RESULTADOS}

Aquífero é uma formação geológica, constituída por rochas ou sedimentos, que armazena e transmite água por seus poros ou fraturas (Feitosa et al., 2008). Na natureza, as transferências de água entre os diversos sistemas aquíferos e a rede de escoamento superficial dependem das relações definidas pela distribuição espacial dos potenciais hidráulicos, e pelos tipos litológicos que afloram ao longo dos rios e córregos (Monteiro et. al., 2007). Os 
resultados obtidos apresentam informações físico-químicas e isotópicas de 19 amostras de água, coletadas em três diferentes compartimentos hídricos da área de estudo, referentes ao sistema de escoamento superficial, Sistema Aquífero de Leques Aluviais, e Sistema Aquífero Rio Bonito (Figura 8). As amostras de água subterrânea foram obtidas em poços de monitoramento instalados nos sistemas aquíferos de Leques Aluviais e Rio Bonito conforme observado na figura 9. Destaca-se que a posição do filtro instalado se encontra sempre na base dos poços. A presença de artesianismo, que é a elevação do nível potenciométrico acima do nível saturado do aquífero, evidencia o confinamento do sistema aquífero Rio Bonito nos locais perfurados. Observa-se que a entrada de água dos poços ocorre somente junto ao filtro, sendo que o restante do espaço anelar foi devidamente cimentado (Figura 9).

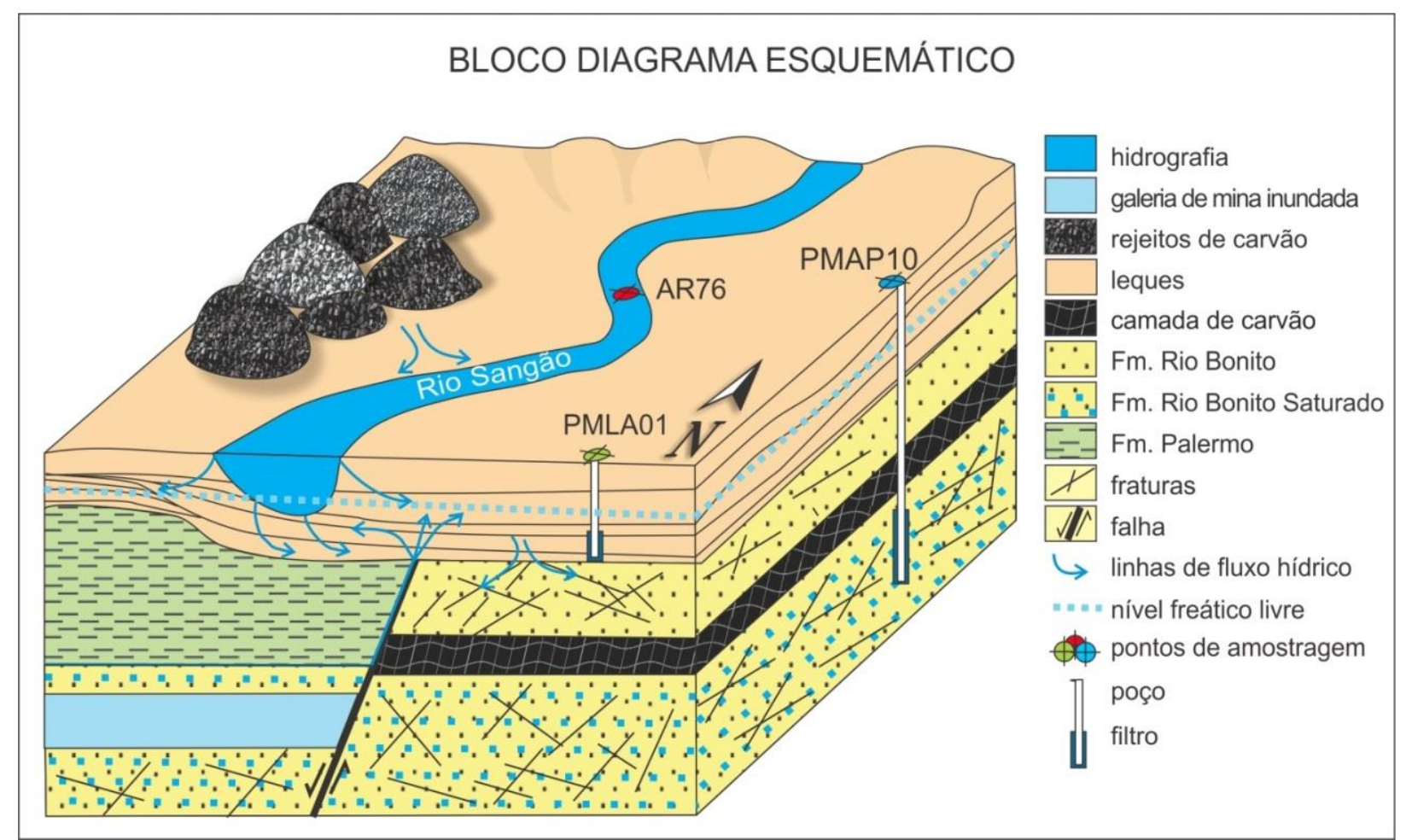

Figura 8 - Representação dos compartimentos hídricos (escoamento superficial e aquíferos de Leques Aluviais e Rio Bonito) presentes na área de estudo e sistemática de amostragem.

Os resultados físico-químicos e isotópicos foram agrupados conforme os compartimentos hídricos (águas superficiais, Sistema Aquífero de Leques Aluviais e Sistema Aquífero Rio Bonito) e são apresentados na Tabela 1. Também são relacionados, com objetivo de comparação, resultados de duas amostras das águas do aquífero Rio Bonito de uma região semelhante, situada no Rio Grande do Sul, porém sem atividades de mineração (Goffermann, 2013). Os valores das amostras de Goffermann (2013) para o aquífero Rio Bonito no Rio Grande do Sul, tem $\mathrm{pH}$ de 6,90 e 8,02, condutividade elétrica de 428,00 e $2.020,00 \square \mathrm{S} / \mathrm{cm}$, sulfato de $14,80 \mathrm{mg} / \mathrm{L}$, ferro de 0,08 a 0,16 mg/L, alumínio de 0,01 a $0,03 \mathrm{mg} / \mathrm{L}$, manganês de 0,04 a $0,06 \mathrm{mg} / \mathrm{L}$. Por estarem em área de ocorrência do aquífero Rio Bonito, livre de atividades de mineração, estas amostras foram utilizadas de forma comparativa com as águas do Rio Bonito da área de estudo.
Em relação ao $\mathrm{pH}$, as amostras analisadas no compartimento de água superficial variam de 2,75 a 7,28, sendo que as amostras AR68, AR76, AR78 e AR85, coletadas nos rios dos Porcos e Sangão, possuem o $\mathrm{pH}$ de 2 a 4, caracterizando influência da drenagem ácida de mina (Figura 10), conforme critérios de Farfan et al. (2004). As amostras dos compartimentos de água subterrânea, em relação ao $\mathrm{pH}$ variaram de 4,65 a 8,19 e se encontram acima do valor característico de drenagem ácida.

Em relação à concentração de sulfato $\left(\mathrm{SO}_{4}\right)$, as amostras do compartimento superficial apresentaram altas concentrações que variam de 41,98 a $3.840,23 \mathrm{mg} / \mathrm{L}$, estando acima do limite considerado para trechos de rios sem influência da mineração, conforme figura 11. Duas das quatro amostras de água subterrânea do Aquífero dos Leques Aluviais (PMLA02 e PMLA04) apresentaram concentrações acima do limite 
considerado de influência, com valor chegando a duas apresentaram também valores muito acima $1.255,79 \mathrm{mg} / \mathrm{L}$. Nas 9 amostras do do limite (PMAP04 e PMAP05), chegando a compartimento do Sistema Aquífero Rio Bonito, $\quad 714,13 \mathrm{mg} / \mathrm{L}$ (Figura 11).

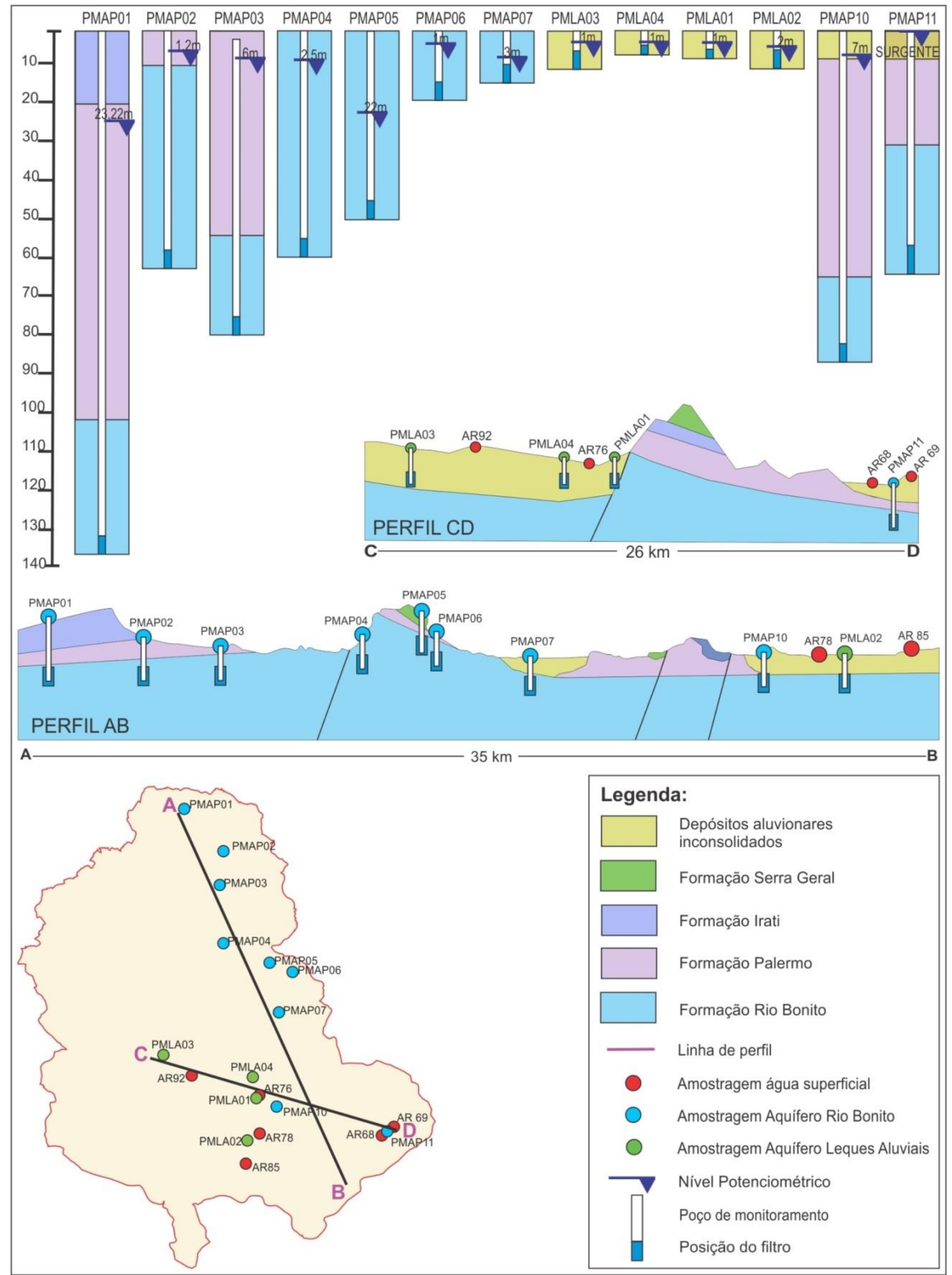

Figura 9 - Poços de monitoramento utilizados para amostragem de água dos Sistemas Aquíferos de Leque e do Sistema Aquífero Rio Bonito, com indicação do nível potenciométrico, profundidade do poço e litologias perfuradas. Representação esquemática da distribuição dos poços e dos pontos de amostragem superficial segundo os perfis $\mathrm{AB}$ e $\mathrm{CD}$. 
Tabela 1 - Resultados das análises físico-químicas e valores de $\delta^{2} \mathrm{H}$ e de $\delta^{18} \mathrm{O}$ das amostras obtidas nos diferentes compartimentos hídricos; erros associados: $\delta^{2} \mathrm{H}(\%)=1.2$ e $\delta^{18} \mathrm{O}(\%)=0.40$; mostras JC 324 e JP 924 são de Goffermann (2013) (ver Figs. 1 e 2). Análise dos metais Cd, As e Hg < Limite de detecção (LQ).

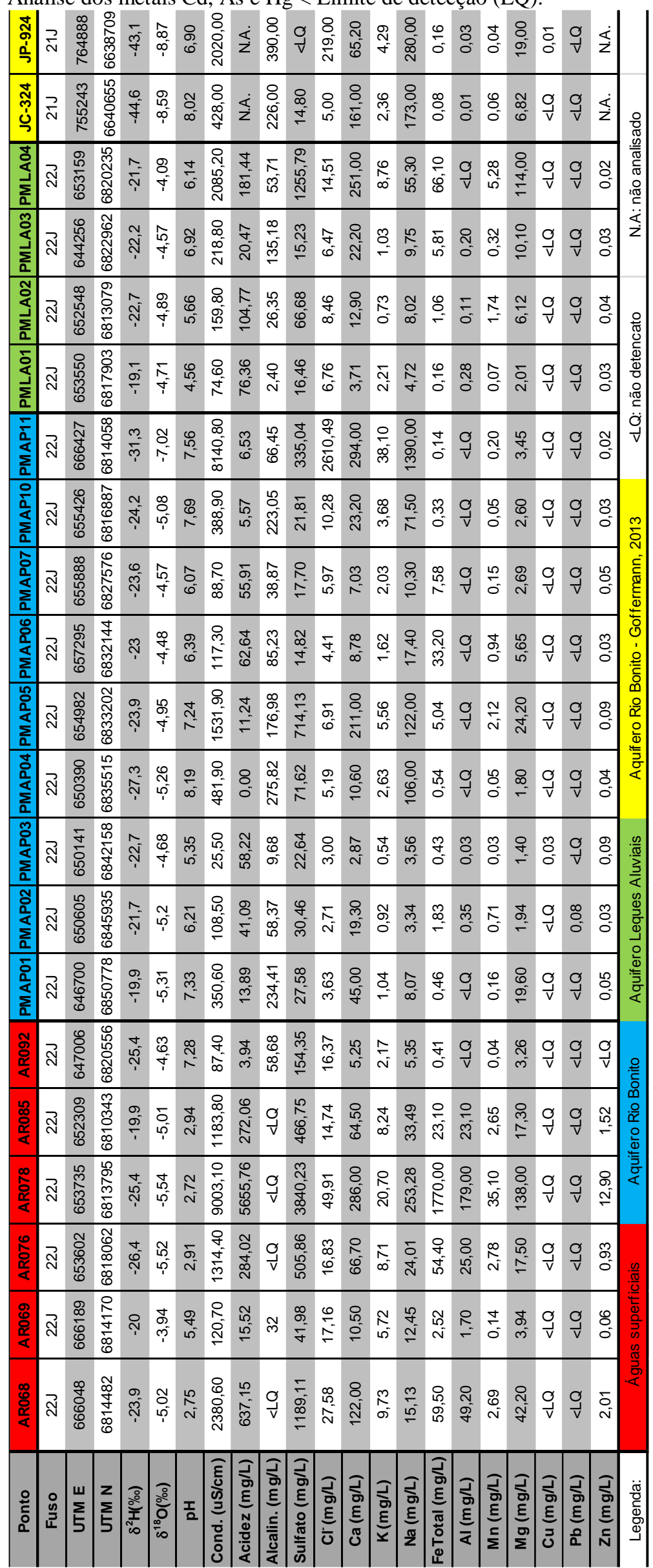




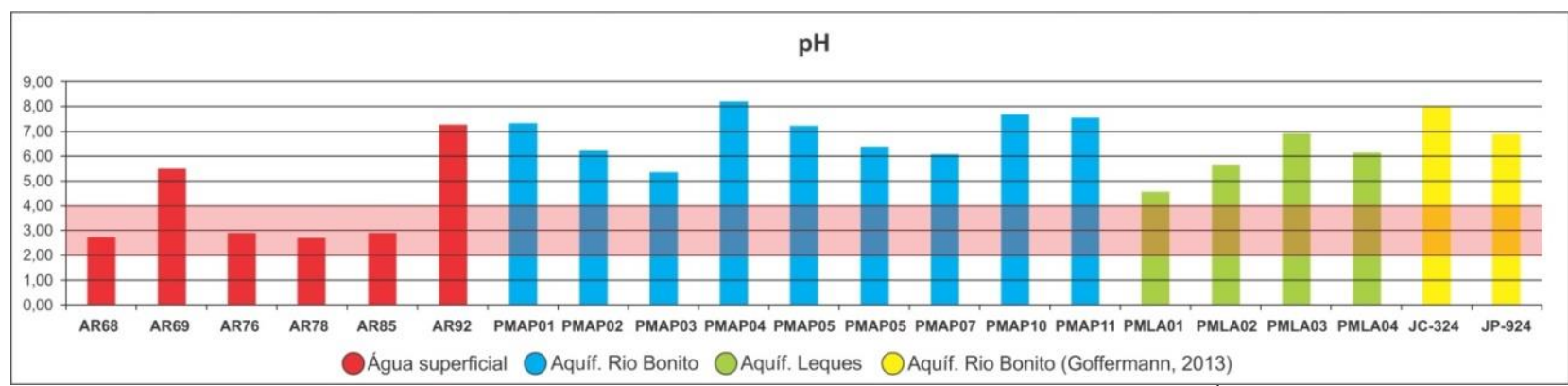

Figura 10 - Valores de pH para as amostras dos compartimentos hídricos da área de estudo. Área marcada pela coloração rosa representa a faixa de $\mathrm{pH}$ característico de drenagem ácida de mina para a região segundo (Farfan, 2004). Observa-se valores de $\mathrm{pH}$ característicos de drenagem ácida de mina nas amostras do compartimento superficial, com exceção dos pontos AR69 e AR92. As amostras de água subterrânea possuem valores de pH acima da faixa de influência.

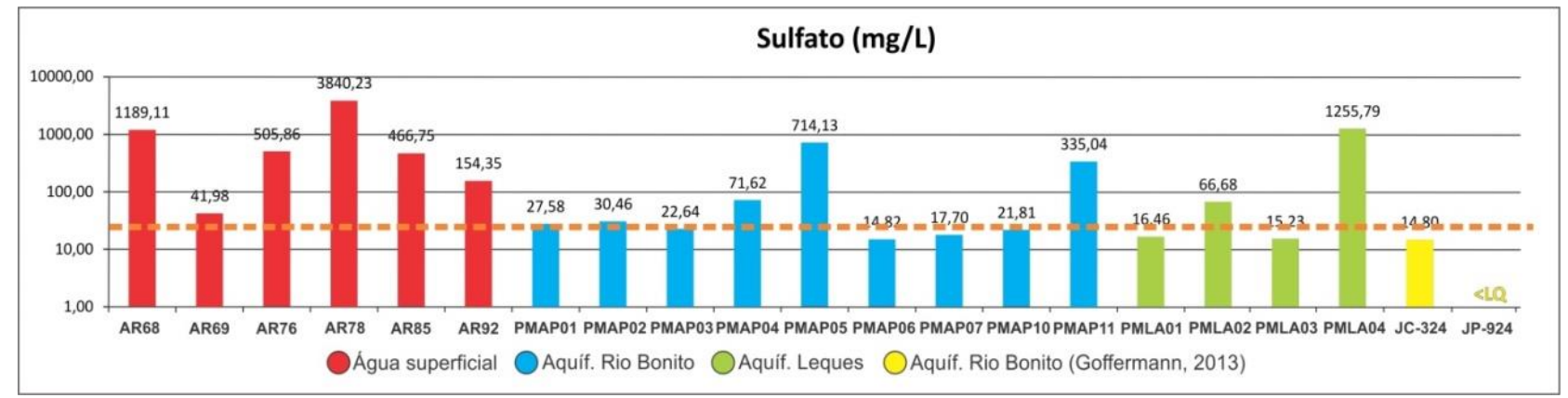

Figura 11 - Concentrações de sulfato das amostras analisadas. A linha pontilhada representa o limite máximo de concentração considerado para trechos de rio sem influência da mineração de carvão $\left(\mathrm{SO}_{4}<25.0 \mathrm{mg} / \mathrm{L}\right.$ segundo Farfan et al., 2004). Observa-se que as amostras do compartimento superficial estão todas acima deste limite. As amostras dos leques possuem duas amostras acima do limite (PMLA02 e PMLA04). As amostras do sistema aquífero Rio Bonito possuem 3 amostras acima do limite (PMAP04, PMAP05 e PMAP11).

Em relação à concentração de metais, observa-se que os maiores valores ocorrem nas amostras do compartimento de água superficial. Neste compartimento, todas as concentrações estão acima ou muito próximas dos limites considerados para águas sem influência da drenagem ácida comparando com Farfan et al. (2004). No aquífero de leques aluviais, ocorrem concentrações de ferro acima do limite nas amostras PMLA03 e PMLA04 (Figura 1 e 2). As amostras do sistema aquífero Rio Bonito apresentam as menores concentrações de metais, com grande parte das amostras com ausência de alumínio. A concentração de ferro encontra-se acima do limite nas amostras PMAP05, PMAP06 e PMAP07. Em todos os compartimentos hídricos, observa-se a presença constante de manganês, sempre acima do limite considerado para influência da mineração, com valores entre 0,03 a 35,10 mg/L (Figura 12).

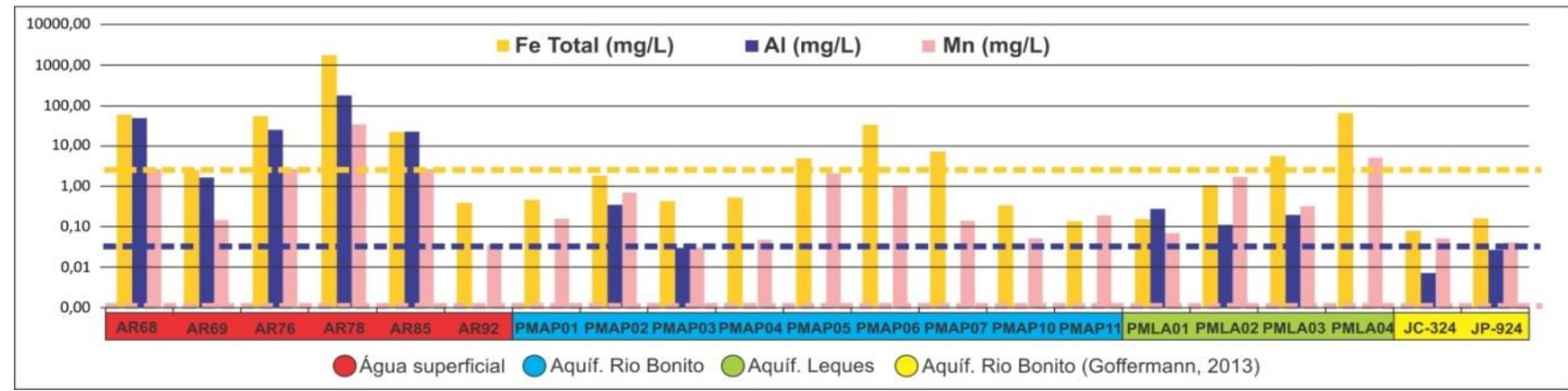

Figura 12 - Concentrações de Fe, Al e Mn totais das amostras analisadas. A linha pontilhada representa o limite máximo de concentração considerado para trechos de rio sem influência da mineração de carvão, (Fe<4.0 mg/L, Al<0,5 mg/L e Mn não detectado, conforme Farfan et al., 2004). De um modo geral, observa-se uma maior concentração destes metais nas amostras de água superficial, e menor concentração nas amostras do Aquífero Rio Bonito.

Razões isotópicas do oxigênio e do hidrogênio da água são muito utilizadas como traçadores para o entendimento de processos hidrogeológicos como precipitação, recargas subterrâneas, águas superficiais, interações entre águas de diversos compartimentos e hidrologia nas bacias hidrográficas.

Comparações entre as composições isotópicas 
das precipitações e das águas subterrâneas são uma excelente ferramenta para avaliar mecanismos de recarga e de contaminação (Yeh et al., 2014).

As razões isotópicas das amostras analisadas indicam que os valores de $\delta^{2} \mathrm{H}$ situam-se entre 19,1 a $-31,3 \%$ o enquanto as de $\delta^{18} \mathrm{O}$ variaram entre -3,94 a -7,02 \%о. As amostras analisadas têm composição isotópica próxima à reta GMLV (Craig, 1961) e demonstram grande similaridade no fracionamento isotópico (Figura 13). A tendência central das razões isotópicas para $\delta^{2} \mathrm{H}$ é de $-23,38$ e $\delta^{18} \mathrm{O}$ é $-4,97$. Verifica-se que o ponto PMAP11 é o único ponto analisado que se afasta dos valores médios, possuindo valores levemente mais negativos, com $\delta^{2} \mathrm{H}$ de $-31,3$ e $\delta^{18} \mathrm{O}$ é -7,02. Em termos comparativos, as amostras de Goffermann (2013) no aquífero Rio Bonito possuem razões ainda mais negativos, com valores de $\delta^{2} \mathrm{H}$ de $-44,6$ e $\delta^{18} \mathrm{O}-8,59$.
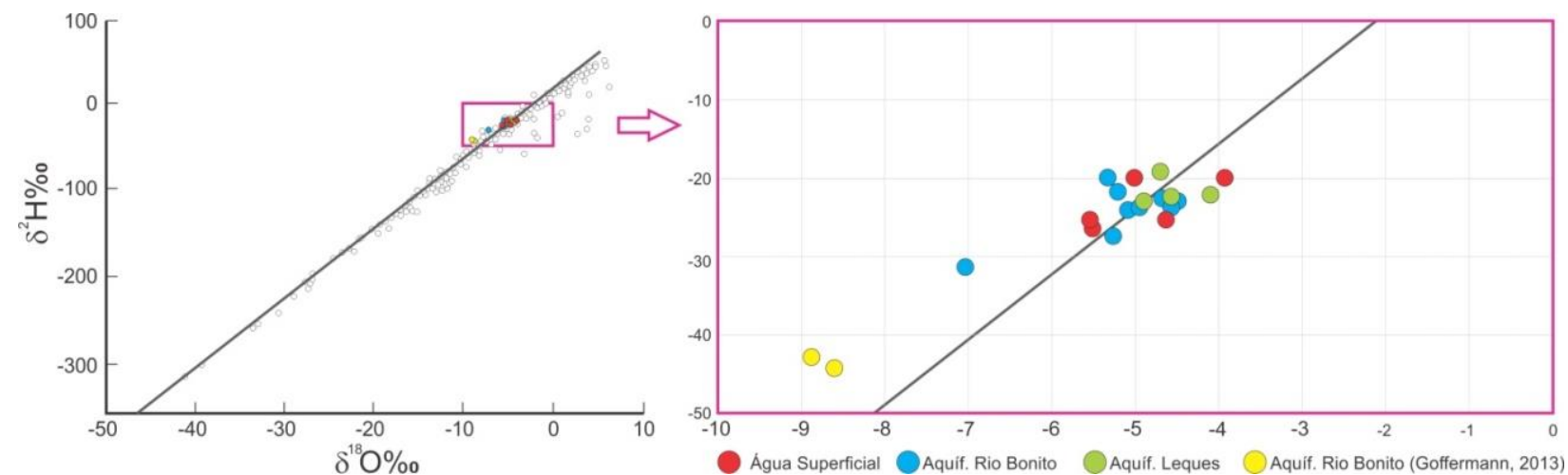

Figura 13 - Correlação entre as composições isotópicas de $\delta^{18} \mathrm{O}$ e $\delta^{2} \mathrm{H}$ nas águas subterrâneas do Sistema Aquífero Rio Bonito, Sistema Aquífero de Leques Aluviais e águas superficiais. Observa-se que as amostras dos diversos compartimentos hídricos apresentam valores isotópicos relativamente próximos, definindo um campo único, e se ajustam a reta GMWL (Craig, 1961). Somente a amostra PMAP11 é diferenciada pois os valores de $\delta^{18} \mathrm{O}$ e $\delta^{2} \mathrm{H}$ são mais negativos ou isotopicamente mais leves em relação ao padrão SMOW.

\section{DISCUSSÃO}

$\mathrm{Na}$ região de estudo há três distintos pelo escoamento superficial. As análises obtidas compartimentos hídricos representados por dois das águas destes compartimentos foram plotadas sistemas aquíferos (Rio Bonito e Leques no Diagrama de Piper (Mobus, 2002) para fins de Aluviais), e outro compartimento representado classificação hidroquímica (Figura 14).

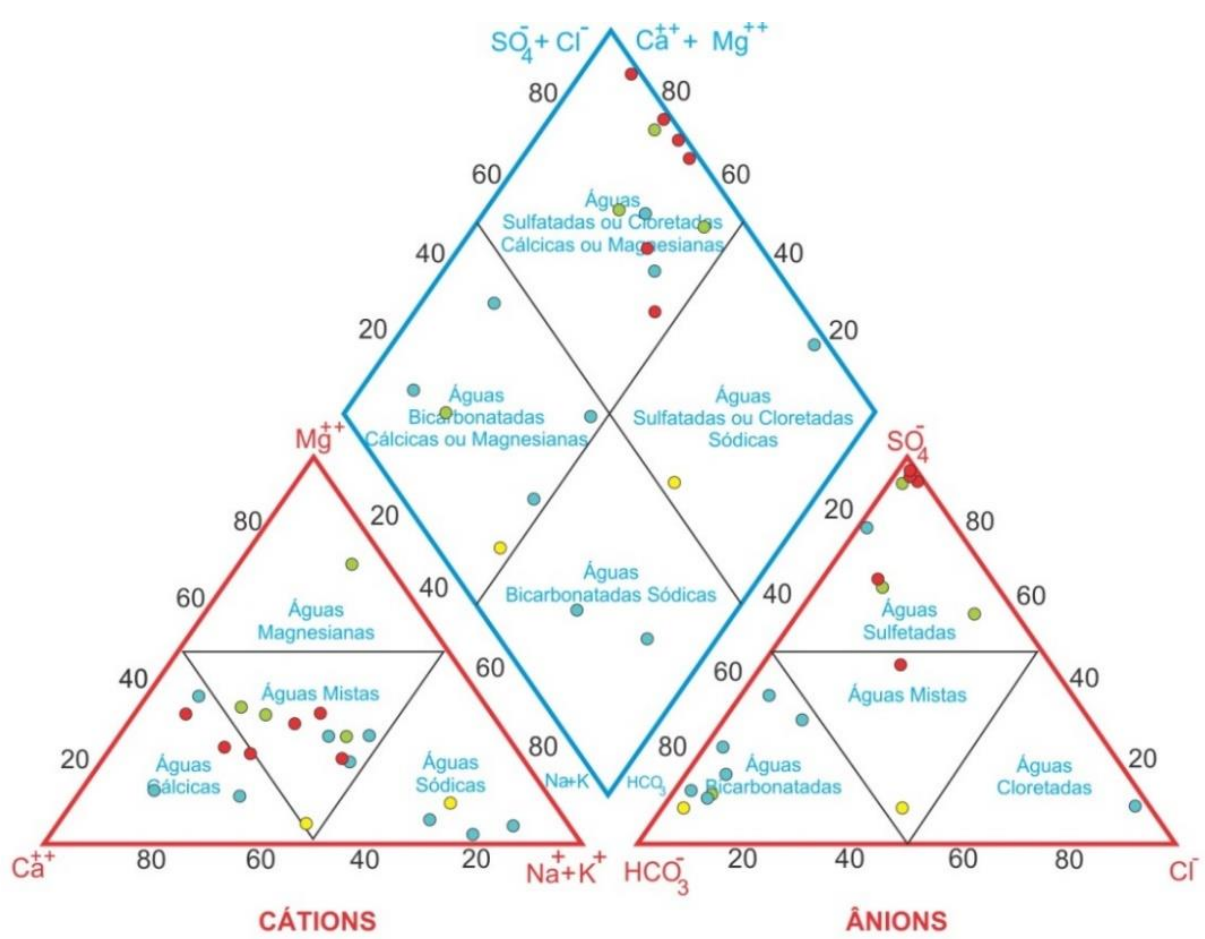

Figura 14 - Classificação hidroquímica das amostras analisadas segundo Diagrama de Pipper (Mobus, 2002). 
De acordo com a classificação hidroquímica do Digrama de Piper (Figura 14) verifica-se que as águas superficiais analisadas estão no campo das águas sulfatadas cálcicas. Este quimismo está associado à presença constante de rejeitos da mineração do carvão nas bacias de contribuição dos pontos amostrados.

A classificação hidroquímica das águas do Sistema Aquífero de Leques Aluviais indica que as amostras PMLA01, PMLA03 e PMLA04 são águas sulfatadas, e a amostra PMLA02 é do tipo bicarbonatada magnesiana (Figura 14).

As águas deste sistema circulam pelo manto de alteração e pelos depósitos cenozoicos que cobrem as litologias da Bacia do Paraná presentes na área. São aquíferos livres, ou semi confinados, com condutividade hidráulica elevada, espessuras que variam entre 5 e $40 \mathrm{~m}$, extensão variável, e alta vulnerabilidade à contaminação. Devido ao pouco tempo de residência suas águas apresentam tendência naturalmente à baixa condutividade elétrica (inferior a $100 \square \mathrm{S} / \mathrm{cm}$ ), porém quando influenciadas pela drenagem ácida de mina, são encontrados valores de condutividade elétrica da ordem de $2.000 \square \mathrm{S} / \mathrm{cm}$. Isto pode ser verificado na amostra PMLA04 dos leques aluviais (ver Figura 4).

A classificação hidroquímica das águas do Sistema Aquífero Rio Bonito indica que as amostras PMAP01, PMAP02, PMAP06 e PMAP07 correspondem a Águas Bicarbonatadas Cálcicas, as amostras PMAP04 e PMAP10 a Águas Bicarbonatadas Sódicas, as amostras PMAP03 e PMAP05 a Águas Sulfatadas ou Cloretadas Cálcicas, e a amostra PMAP11 a

Água Sulfatada ou Cloretada Sódica. A qualidade das águas deste aquífero originalmente está associada a ambientes confinados, com baixa velocidade de fluxo e longos tempos de residência (5.400 a 11.310 anos), segundo os dados apresentados por Goffermann (2013), para área análoga.

$\mathrm{Na}$ área de estudo, a condição estrutural está relacionada a eventos tectônicos de natureza rúptil, que tiveram início com a abertura gondwânica, e se encerraram com o soerguimento regional do Domo de Lages (Petry et al., 2017). Esta tectônica resultou no soerguimento das litologias gondwânicas, permitindo que a Formação Rio Bonito aflorasse em uma faixa norte-sul, com presença constante de descontinuidades e falhamentos, como pode ser visualizado nos perfis esquemáticos da Figura 9. O resultado desta condição estrutural permite que o Aquífero Rio Bonito na área de estudo apresente uma condição de fluxo mais dinâmico em relação às áreas confinadas das demais porções da Bacia do Paraná, diminuindo os tempos de residência, e por consequência os valores de salinidade.

Observa-se, no entanto, que a presença da drenagem ácida de mina, modifica localmente as condições físico-químicas naturais deste sistema aquífero. Esta modificação se traduz na elevação da salinidade, e na transformação das águas dos tipos bicarbonatados em tipos sulfatados, devido ao incremento do sulfato resultante da oxidação dos sulfetos metálicos. A figura 15 demonstra a relação entre o aumento da condutividade elétrica e a presença de sulfato nas amostras obtidas na área de estudo.

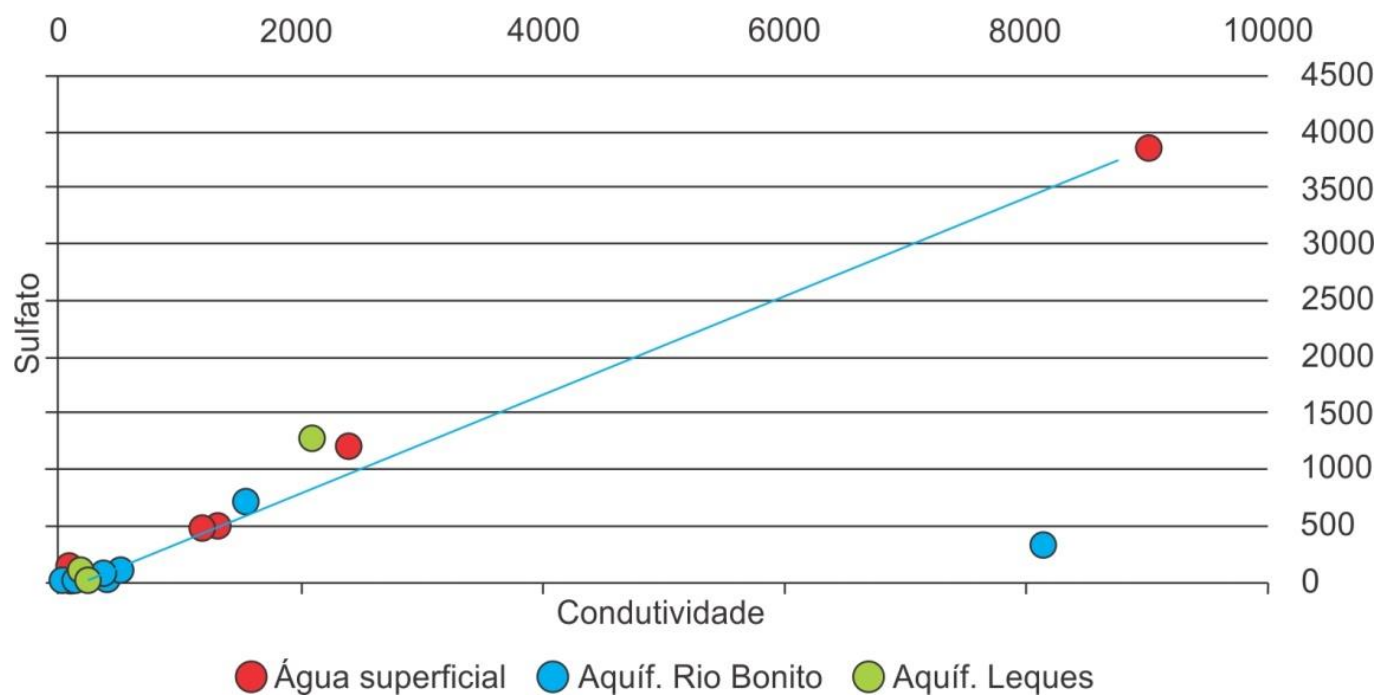

Figura 15 - Relação entre a condutividade elétrica e a presença de sulfato nas águas. Apenas na amostra PMAP11 a relação não é mantida, visto que este poço possui maior grau de confinamento, e a elevada condutividade está ligada a presença de sódio e cloreto, de origem discutível. 
Para fins de comparação, as amostras dos poços do Sistema Aquífero Rio Bonito da Bacia Carbonífera são referidas às amostras do aquífero Rio Bonito na região de São Gabriel (Rio Grande do Sul) onde não há atividades de mineração de carvão (Goffermann, 2013). Estas amostras foram classificadas como Bicarbonatada Cálcica ou Magnesiana e Sulfetada ou Cloretada Sódica (Figura 14).

Conclui-se que de um modo geral, as águas deste sistema aquífero podem conter quantidades de sulfato natural, mesmo sem a presença de atividades de mineração. A presença de 27,58 $\mathrm{mg} / \mathrm{L}$ de sulfato na água do poço PMAP01, que situa-se a montante da região mineira $\mathrm{e}$ corresponde ao ponto "branco" (Figura 4), também colabora com esta indicação, e dificulta o estabelecimento de um background para as águas subterrâneas da região carbonífera.

Em particular, constata-se que existe uma maior contaminação por drenagem ácida de mina no poço PMAP06 do aquífero Rio Bonito, devido à elevação da concentração de ferro e manganês (Figura 16A). A identificação da origem das elevadas concentrações de sódio, cloreto e sulfato na amostra do PMAP11 (Figura 16B) necessitará de estudo específico. Neste poço, a proximidade da linha de costa e presença de sedimentos praiais, pode levar à interpretação de contribuição marinha, mas por outro lado, o artesianismo surgente presente neste poço evidencia um grau mais elevado de confinamento, o que sugere que a contaminação tenha origem em galerias de minas subterrâneas.

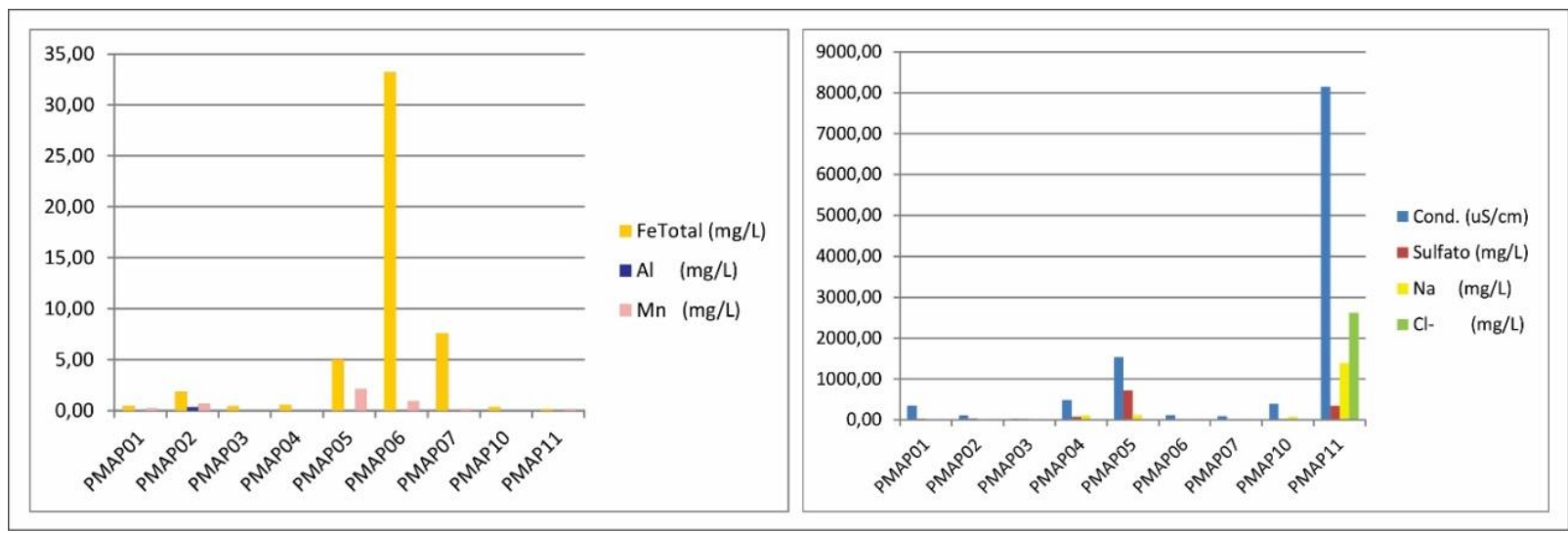

Figura 16 - A) Concentração de metais em águas superficiais; B) Condutividade elétrica, concentração de sulfato, cloreto e sódio nas amostras de água do Aquífero Rio Bonito.

Os resultados isotópicos de $\delta^{2} \mathrm{H}$ e $\delta^{18} \mathrm{O}$ demonstram grande similaridade entre as águas dos diversos compartimentos hídricos estudados, e não foram observadas diferenças de fracionamento entre as água subterrâneas e as águas superficiais.

Sabe-se que a recarga de um aquífero é obtida através da água de precipitação e a sua composição isotópica é semelhante à composição isotópica das águas meteóricas. Podem, no entanto, ocorrer desvios relativos à composição das águas meteóricas que são associados com processos de evaporação e com outros mecanismos de recarga (Clark \& Fritz, 1997). Na figura 13 estão representados os valores de $\delta^{2} \mathrm{H} \mathrm{e}$ $\delta^{18} \mathrm{O}$ das amostras de água recolhidas na área de estudo, tendo como termo de comparação a Linha Mundial das Águas Meteóricas (GMWL de Craig, 1961).

Pode-se verificar que os valores isotópicos obtidos para as águas da bacia carbonífera têm uma aproximação razoável com a GMWL
(Figura 13) podendo então ser representativos das águas meteóricas. Isto leva a supor que a recarga dos aquíferos seja, pelo menos em grande parte, obtida através das águas de precipitação. As amostras que mais se distanciam da reta GMWL podem estar relacionadas a diferenças de intensidade dos processos de evaporação (valores mais negativos são produzidos por maiores processos de evaporação). Importante salientar que o número de pontos analisados não é suficiente para traçar a reta meteórica da região de estudo, o que permitiria uma comparação mais real.

Como destaque, observam-se os valores mais negativos para as razões $\delta^{2} \mathrm{H}$ e $\delta^{18} \mathrm{O}$ no poço PMAPAR11, que representa o aquífero Rio Bonito com fenômeno de surgência, levando a crer que neste ponto ocorram as águas com maior tempo de residência deste sistema aquífero para a área de estudo. Em complemento, observa-se que os valores de $\delta^{2} \mathrm{H}$ e $\delta^{18} \mathrm{O}$ mais negativos para as amostras do aquífero Rio Bonito são da região 
de São Gabriel (Goffermann, 2013), que sugere um maior grau de confinamento e maior tempo de residência, quando comparadas às águas da bacia carbonífera catarinense (Figura 13).

Com relação à interação entre os compartimentos de água superficial e do Aquífero Rio Bonito, Krebs \& Gomes (2005) identificaram assinaturas hidroquímicas semelhantes em poços deste aquífero e em águas do Rio Mãe Luzia. Para os autores isto sugere que em períodos de estiagem, o Sistema Aquífero Rio Bonito poderia alimentar as drenagens superficiais por meio do fluxo de base. Leão \& Krebs (2017) também demonstram, por meio de uso de traçadores, a conexão entre a água de poços instalados no aquífero Rio Bonito e as águas superficiais, com condutividade hidráulica (K) da ordem de $6,66 \mathrm{~m} /$ dia. Estas sugestões confirmam os dados hidroquímicos e isotópicos obtidos neste estudo, que demonstram grande semelhança entre as águas subterrâneas e águas meteóricas, sugerindo intensa circulação entre os distintos compartimentos hídricos.

As águas do aquífero de leques aluviais são influenciadas pela mistura entre as águas de recarga provenientes dos rios e córregos afetados pela mineração, e pela recarga direta da água da chuva. Isto pode ser comprovado pelos resultados isotópicos que acompanham a linha das águas meteóricas (Figura 17). Embora não se tenha evidências da recarga do Aquífero de Leques através do Aquífero Rio Bonito, este movimento ascendente não pode ser descartado, visto que a potenciometria dos poços perfurados no Sistema Aquífero Rio Bonito, sempre indica uma tendência ao artesianismo.
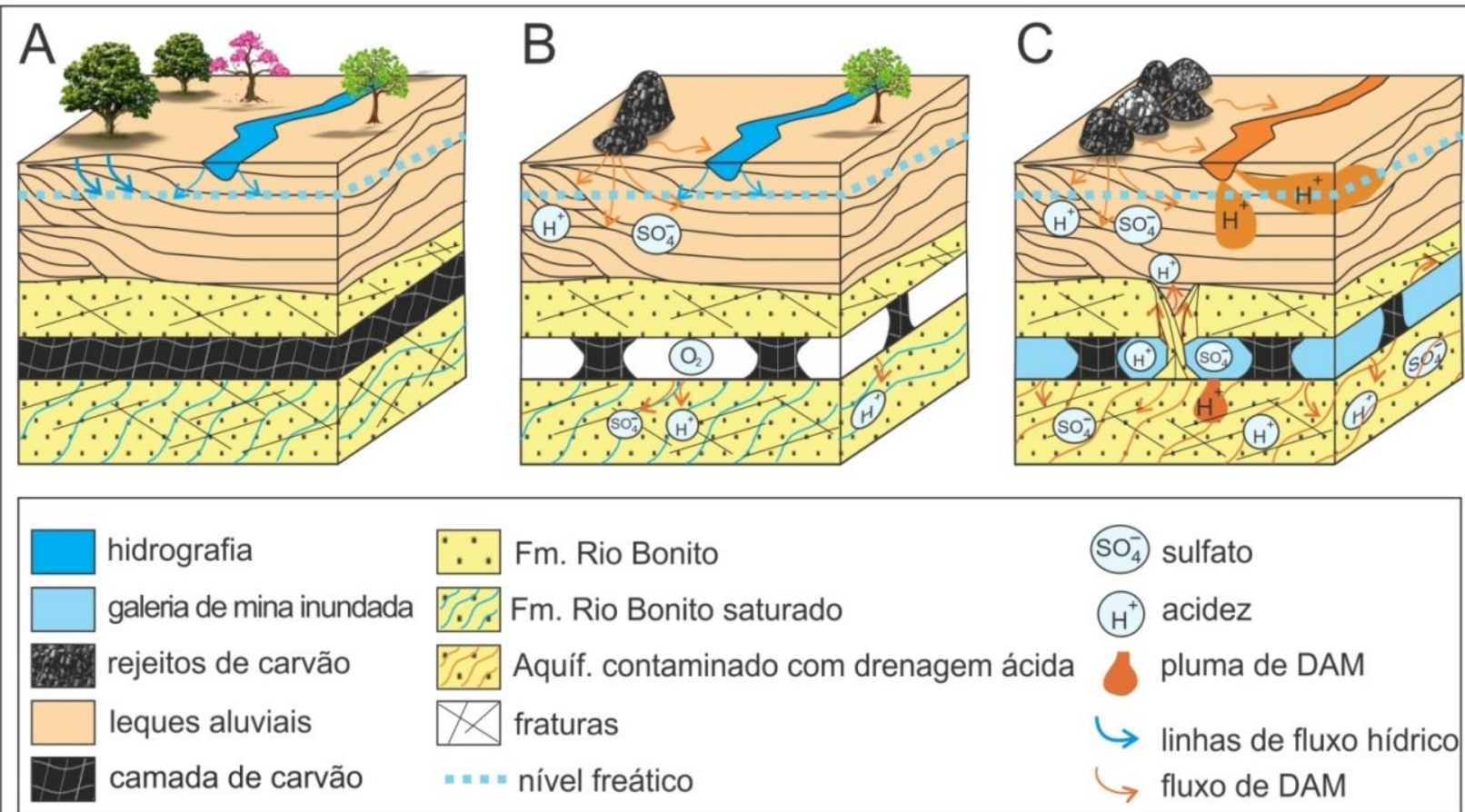

Figura 17 - Bloco diagrama esquemático da evolução da geração e migração da drenagem ácida de mina (DAM). A) Camada de carvão preservada, sem atividades de mineração; B) Instalação das galerias de mina para lavra subterrânea do carvão e exposição atmosférica dos rejeitos, com início dos processos de geração de drenagem ácida de mina (DAM). C) Fluxo e migração da drenagem ácida de mina (DAM) com processos interconexão dos sistemas aquíferos devido a abatimento das galerias, e degradação dos ambientes aquáticos.

\section{CONCLUSÕES}

As águas dos compartimentos de água superficial e do aquífero de Leques Aluviais estão fortemente sob a influência da drenagem ácida de mina, que modifica os parâmetros de $\mathrm{pH}$, condutividade elétrica e aumenta as concentrações de sulfato, Fe, $\mathrm{Al}$ e $\mathrm{Mn}$. De um modo geral, observa-se que o incremento de $\mathrm{SO}_{4}{ }^{-}$ originado pela oxidação de sulfetos presentes no rejeito de carvão é responsável pela modificação de águas bicarbonatados em águas sulfatadas.

Já os processos de subsidência causados pelas minas subterrâneas são responsáveis por intensificar localmente a circulação e a mistura entre os diversos compartimentos de água superficial e subterrânea, embora grande parte das águas do aquífero Rio Bonito não se apresente afetada pela drenagem ácida de de mina. 
As análises isotópicas demonstram que as águas dos diferentes compartimentos têm grau de fracionamento isotópico $(\mathrm{O}$ e $\mathrm{H})$ semelhante ao das águas meteóricas, indicando uma intensa circulação entre os ambientes superficiais e subterrâneos.

\section{AGRADECIMENTOS}

Os autores agradecem ao Programa de Pós-Graduação em Geociências (PPGGEO) da Universidade Federal do Rio Grande do Sul (UFRGS) e ao Serviço Geológico do Brasil (CPRM).

\section{REFERÊNCIAS}

AMARAL, J.E. \& KREBS, A.S.J. Drenagem Ácida da Mineração de Carvão e sua Interrelação com Metais Pesados e Recargas de Aquíferos na Bacia Carbonífera do Estado de Santa Catarina. In: CONGRESSO BRASILEIRO DE ÁGUAS SUBTERRÂNEAS XVI e ENCONTRO NACIONAL DE PERFURADORES DE POÇOS, XVII São Luís, 2010. Anais... São Luís: Sociedade Brasileira Águas subterrânea, 2010.

AMERICAN PUBLIC HEALTH ASSOCIATION. Standard methods for the examination of water and wastewater. 20 ed. Washington: APHA, 937 p, 1998.

ANEEL - Atlas de Energia Elétrica do Brasil - Parte III Fontes Não Renováveis - Agência Nacional de Energia Elétrica. Disp. em www.aneel.gov.br, 2017.

ASSOCIAÇÃO BRASILEIRA DE NORMAS TÉCNICAS. NBR 15.495-1. Poços de Monitoramento de Águas Subterrâneas em Aquíferos Granulares - Parte 1: Projeto e Construção. Rio de Janeiro, 25 p., 2007.

ASSOCIAÇÃO BRASILEIRA DE NORMAS TÉCNICAS. NBR 15.847. Amostragem de água subterrânea em poços de monitoramento - Métodos de purga. Rio de Janeiro, 20 p., 2010.

BELOLLI, M., QUADROS, J., GUIDI, A. História do Carvão de Santa Catarina. Criciúma: Imprensa Oficial do Estado de Santa Catarina. 2002.

BITENCOURT, M.F., BONGIOLO, E.M., PHILIPP, R.P., MORALES, L., GRAFULHA, L.F.M., RUBERT, R.R., MELO, C.L. LUFT Jr, L.J. Estratigrafia do Batólito Florianópolis, Cinturão Dom Feliciano, na Região de Garopaba-Paulo Lopes, SC. Pesquisas em Geociencias, v. 35 , p. 109, 2008.

CHRISTOPHE, L. GARDIEN, V., RIGAUDIER, T., FOUREL, F., MARTINEAU, F., CROS, A. Oxygen isotope fractionation and equilibration kinetics between $\mathrm{CO}_{2}$ and $\mathrm{H}_{2} \mathrm{O}$ as a function of salinity of aqueous solutions. Chemical Geology, v. 264, v. 1-4, p. 122-126, 2009.

CLARK, I. \& FRITZ, P. Environmental Isotopes in Hydrogeology, ed. Lewis Publishers, U.S.A., 328 p, 1997.

CPRM - Serviço Geológico do Brasil. Relatório Técnico de Perfuração de Poços de Monitoramento. Convênio $\mathrm{n}^{\mathrm{o}}$ 003/2014-SMCQ/MMA - Criciúma, SC. Documento Interno, 2017.

CRAIG, H. Isotopic variation in meteoric water. Science, v. 133, p. 1702-1708, 1961.

DNPM - Departamento Nacional da Produção Mineral. Mapa das áreas mineradas em subsolo da região carbonífera de Santa Catarina. DNPM/SC - Não publicado, 2009.

FARFAN, J.R., FILHO, B.O., SOUZA, V.P. Avaliação do Potencial de Drenagem Ácida de rejeitos da Indústria Mineral. Rio de Janeiro: CETEM, 58 p, 2004.

FEITOSA, F.A.C., MANOEL FILHO, J., FEITOSA, E.C., DEMÉTRIO, J.G. Hidrogeologia: conceitos e aplicações. 3.ed. Rio de Janeiro: CPRM, LABHID-UFPE. 812 p, 2008

GOFFERMANN, M. Caracterização hidrogeológica e hidroquímica das águas subterrâneas da região de São Gabriel, RS Porto Alegre, 2013. Dissertação (Mestrado) IGEO/UFRGS
GTA - Grupo Técnico de Assessoramento. 11 ${ }^{\circ}$ Relatório de Monitoramento dos Indicadores Ambientais. Volume 1. Ação Civil Pública (2018) no 93.8000.533-4. Proc. de cumprimento de sentença $\mathrm{n}^{\circ}$ 2000.72.04.002543-9. 2018.

IBGE - Instituto Brasileiro de Geografia e Estatística. Base cartográfica contínua do Brasil, ao milionésimo - BCIM - $5^{\text {a }}$ versão, 2016.

KREBS A.S.J. Contribuição ao conhecimento dos recursos hídricos subterrâneos da bacia hidrográfica do rio Araranguá, SC. Florianópolis, Florianópolis, 2004. Tese (Doutorado), Universidade Federal de Santa Catarina.

KREBS, A.S.J., GOMES, C.B.J. Caracterização hidroquímica das águas do aquífero Rio Bonito na Região Carbonífera de Santa Catarina. In: SIMPÓSIO BRASILEIRO DE RECURSOS HÍDRICOS. João Pessoa, 2005. Anais...João Pessoa: Sociedade Brasileira de Geologia, v. 16.

LEÃO, M.I. \& KREBS, A.S.J. Estudo da conexão entre águas subterrâneas e superficiais usando traçador na área do Campo Vila Funil, Siderópolis-SC, V CBCM, 2017.

MACHADO, J.L.F. Mapa Hidrogeológico do Estado de Santa Catarina. Porto Alegre: CPRM, 2013.

MACHADO, J. L. F. \& FREITAS, M.A. Projeto Mapa Hidrogeológico do Rio Grande do Sul. Relatório final. Porto Alegre: CPRM, 2005.

MELLO, J.W.V.; DUARTE H.A., LADEIRA, A.C.Q. Origem e Controle do Fenômeno Drenagem Ácida de Mina. In: Cadernos Temáticos de Química Nova na Escola, n 8, p. 24 29. 2014.

MILANI, E.J., MELO, J.H.G., SOUZA, P.A., FERNANDES, L.A., FRANÇA, A.B. Bacia do Paraná. In: Cartas Estratigráficas. Boletim de Geociências da Petrobras, Rio de Janeiro, v. 15, n. 2, p. 265-287, 2007.

MOBUS, G. Qualigraf: programa para análise da qualidade da água. Fortaleza: FUNCENE, 2002.

MONTEIRO, J.P., SILVA, J.M., GUERREIRO, P., MARTINS, J., REIS, E. Modelação de relações entre águas superficiais e subterrâneas nos aquíferos do Algarve Central. In: SEMINÁRIO SOBRE ÁGUAS SUBTERRÂNEAS. Lisboa, 2007. Atas...Lisboa: Associação Portuguesa dos Recursos Hídricos.

MÜHLMANN, H., SCHNEIDER, R.L., TOMMASI, E., MEDEIROS, R.A., DAEMON, R.F., NOGUEIRA, A.A. Revisão Estratigráfica da Bacia do Paraná. Ponta Grossa: PETROBRÁS/DESUL. 186 p, 1974.

PETRY, T.S. Geologia estrutural aplicada à mineração subterrânea de carvão: Mina D, Araranguá, SC. Porto Alegre, 2017. Dissertação (Mestrado) IGEO/UFRGS.

YEH, H., LIN, H., LEE, C., HSU, K., WU, C. Identifying Seasonal Groundwater Recharge Using Environmental Stable Isotopes. Water, v. 6, p. 2849-2861, 2014.

Submetido em 10 de outubro de 2018 Aceito em 14 de janeiro de 2020 